\title{
Tangram - Guardado a sete chaves - Construção e Atividades
}

\section{Tangram - Kept under lock and key - Construction and Activities}

DOI: $10.46814 / \operatorname{lajdv3n4-073~}$

Recebimento dos originais: 01/05/2021

Aceitação para publicação: 31/06/2021

\author{
Edmar José Alves
}

Colégio SUPERIUS e Colégio Ressurreição São José do Rio Preto

\section{Rita de Cássia Pavan Lamas}

Universidade Estadual Paulista "Júlio de Mesquita Filho", Instituto de Biociências, Letras e Ciências Exatas, Câmpus de São José do Rio Preto

\section{RESUMO}

Este trabalho tem como objetivo mostrar curiosidades sobre a origem do Tangram, bem como a construção de suas sete peças. Serão propostas atividades baseadas nas peças que compõe o Tangram, com o intuito de desenvolver as habilidades e competências dos alunos do ensino fundamental acerca do conteúdo de áreas de figuras, além da congruência de algumas figuras geométricas.

Palavras chaves: Tangram, Área, Ensino Fundamental.

\section{ABSTRACT}

This work aims to show curiosities about the origin of Tangram, as well as the construction of its seven pieces. Activities based on the pieces that make up the Tangram will be proposed, in order to develop the skills and competencies of elementary school students about the content of figure areas, as well as the congruence of some geometric figures.

Key words: Tangram, Area, Elementary School.

\section{INTRODUÇÃO}

O Tangram é um quebra-cabeça chinês, de origem milenar, mas a sua verdadeira história é guardada a sete chaves, pois a mais antiga publicação com exercícios de Tangram é do inicio do século XIX. Na Ásia, é conhecido por Chi-Chiao "Sete pratos da sabedoria”. Existe até uma Enciclopédia de Tangram que foi escrita por uma mulher, na China, há 130 anos e também várias lendas sobre a origem deste jogo, vejamos algumas delas.

Segundo Gênova (2000) uma delas conta que um chinês deixou cair no chão um pedaço de espelho, de forma quadrada, o qual se quebrou em sete pedaços. Para sua surpresa, com os cacos do espelho, ele poderia dar origem a várias formas conhecidas como animais, plantas, pessoas, objetos, letras, números, figuras geométricas, entre outras.

Outra história conta que o Tangram foi inventado por um homem chamado Tan enquanto tentava consertar os pedaços quebrados de um azulejo de porcelana. 
Porém, segundo alguns estudiosos, onome Tangram é uma corrupção da palavra inglesa obsoleta "Tangram" que significa um puzzie ou quinquilharias. Enquanto, que outros afirmam que é originária da tribo Tanka, onde as pessoas desta tribo da China eram grandes comerciantes envolvidos no comercio do ópio e quando eram visitados pelos mercadores ocidentais eram entretidos pelas medidas Tanka com este quebra-cabeça.

O Tangram chegou rapidamente ao EUA e a Europa e ficou conhecido como o puzzle chinês.Deste então, são criados Tangrans em todos os tipos de materiais, desde cartão até pedra, plástico ou metal. A seguir mostraremos como construir o jogo baseado em Souza (2003), e apresentamos sugestões de atividades.

\section{CONSTRUÇÃO}

1) Em um quadrado, $\mathrm{ABCD}$, traça-se a sua diagonal $\mathrm{DB}$, marca-se o seu ponto médio $\mathrm{O}$ e traça-se a perpendicular a $\mathrm{DB}$ passando por $\mathrm{A}(\mathrm{AO})$;

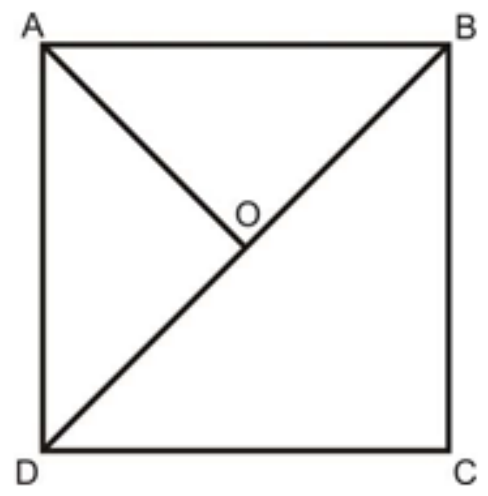

2) Marcam-se os pontos médios, $\mathrm{M}$ e N, dos segmentos OD e OB, respectivamente;

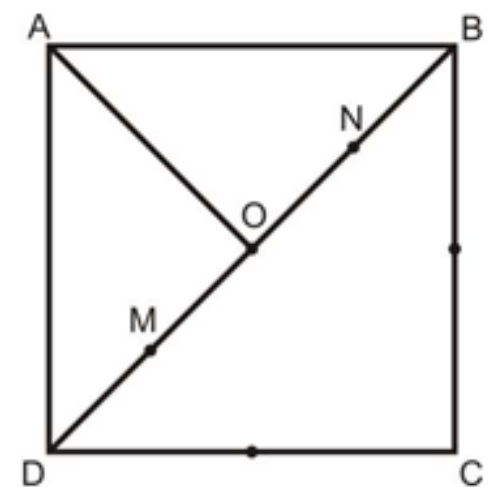


3) Marcam-se os pontos médios, $\mathrm{P}$ e $\mathrm{Q}$, dos segmentos $\mathrm{DC}$ e $\mathrm{CB}$, respectivamente e traçase o segmento PQ e marca-se o seu ponto médio R;

4)

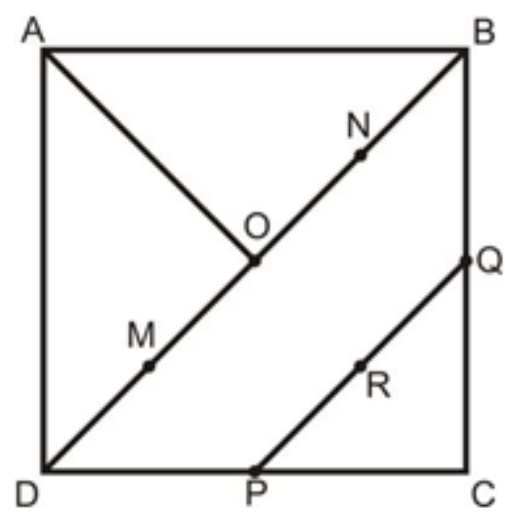

5) Traçam-se os segmentos PM, OR e RN.

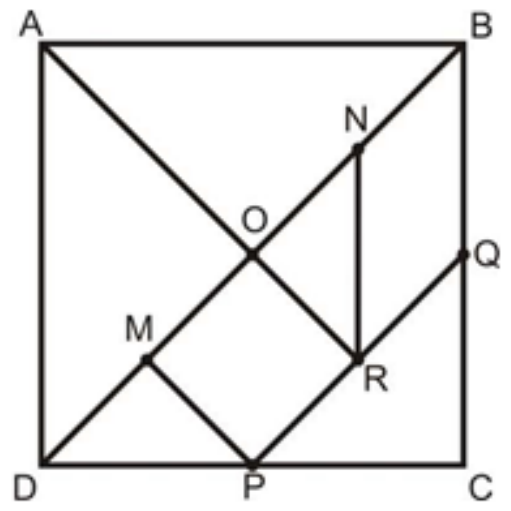

As peças obtidas constituem o Jogo Tangram:

D 5 triângulos: 2 grandes, 1 médio e 2 pequenos;

$>1$ quadrado;

> 1 paralelogramo;

Este material é propício à execução de tarefas de investigação que proporcionam o desenvolvimento de habilidades como: conjecturar, intuir, argumentar, prever, entre outras (MACEDO, 2000).

É importante que se conheça as sete peças deste jogo e os atributos que as relacionam. 
Assim, uma das primeiras atividades a realizar com o tangram, segundo Macedo (1993), deverá ter como objetivo aclassificação das suas peças, o número de lados, o seu comprimento, as peças congruentes, as semelhantes e a congruência dos seus ângulos.

Portanto, Tangram é um jogo guardado a sete chaves, mas que temos inúmeras atividades. Neste trabalho, em particular, são propostas atividades com o tangram que podem ser utilizadas para introduzir ou reforçar o conceito de área no ensino fundamental.

\section{ATIVIDADES}

1) Com as peças deste jogo podemos construir de modo diferente, nove quadrados.

a) Tenta descobrí-los e anote cada modo de construção.

b) Quantos quadrados de diferentes medidas são possíveis construir?

2) Considerando como unidade de área o triângulo menor, determine:

a) a área do triângulo médio;

b) a área do quadrado;

c) a área do paralelogramo.

O que se pode concluir acerca das três figuras anteriores?

3) Com as peças do tangram, determine:

a) um quadrado de área igual à de dois triângulos pequenos;

b) um quadrado de área igual à de quatro triângulos pequenos;

c) um quadrado de área igual à de oito triângulos pequenos.

Com a atividade dois pode ser introduzido para o aluno que a área de uma região plana é a medida da região, delimitada por uma figura plana, e que para medí-la é necessário considerar uma unidade de área. Nesta atividade foi considerada como unidade de área o triângulo menor, para medir as regiões nos ítens a), b) e c), triângulo médio, quadrado e paralelogramo, respectivamente. Por exemplo, o aluno deverá observar que para cobrir (medir) o triângulo médio utilizará dois triângulos menores congruentes. Desta forma, a área do triângulo médio será duas vezes a área do triângulo menor. Com a aquisição desses conhecimentos o aluno será capaz de fazer a atividade três. A introdução de área como proposto é indicada para alunos do sétimo ano do Ensino Fundamental. Uma vez compreendido tal conceito, outras unidades de área podem ser introduzidas. Normalmente nas 
escolas e no nosso cotidiano é utilizado o quadrado como unidade de área, dando significado às unidades de medida $\mathrm{m}^{2}, \mathrm{~km}^{2}$, etc. No oitavo ano, tais atividades seriam para verificar o conhecimento dos alunos, anteriormente adquirido, relativo ao conceito de área. 


\section{REFERÊNCIAS}

GÊNOVA, A. Carlos. Brincando com tangram e origami. São Paulo: Global, 2000.

MACEDO, Lino et al. Aprender com Jogos e Situações-Problemas. Porto Alegre: Artmed, 2000.

MACEDO, Lino. A importância dos jogos de regras para a construção do conhecimento na Escola. São Paulo: IP-USP, 1993.

SOUZA, Eliane R. et al, A Matemática das Sete Peças do Tangram, IME-USP, Volume 7, 2003. 